\title{
Analysis of morbidity and mortality rate in cattle in village areas of Pune division in the Maharashtra state
}

\author{
Yogesh Bangar ${ }^{1}$, T. A. Khan², Amit Kumar Dohare ${ }^{1}$, D. V. Kolekar ${ }^{3}$, Nitin Wakchaure ${ }^{1}$ and B. Singh ${ }^{1}$ \\ 1. Division of Livestock Economics, Statistics \& Information Technology, Indian Veterinary Research Institute, \\ Izatnagar -243122, UP, India; 2. LPM Section, Indian Veterinary Research Institute, Izatnagar -243122, UP, India; \\ 3. Division of Veterinary Extension Education, Indian Veterinary Research Institute, Izatnagar -243122, UP, India \\ Corresponding author: Yogesh Bangar, email: yogeshbangar07@gmail.com \\ YB: yogeshbangar07@gmail.com, TAK: takhan@ivri.res.in, AKD: dr.doharevet@gmail.com, \\ DVK:drdnyanesh45@gmail.com, NW: ntnwakchaure45@gmail.com, BS: bsingh@ivri.res.in
}

Received: 19-01-2013, Revised: 13-02-2013, Accepted: 16-02-2013, Published online: 22-05-2013

\section{How to cite this article:}

Bangar Y, Khan TA, Dohare AK, Kolekar DV, Wakchaure Nand Singh B (2013) Analysis of morbidity and mortality rates in cattle in Pune division of Maharashtra state, Vet World 6(8):512-515, doi:10.5455/vetworld.2013.512-515

\begin{abstract}
Aim: The present study was carried out to analyse morbidity and mortality rate in cattle in village areas of Pune division in the Maharashtra state.

Materials and Methods: The data of total 1538 cattle were collected from 421 cattle owners by stratified two-stage random sampling design and analysed statistically by SAS 9.3 software for evaluation of Chi-square analysis.

Result: Overall morbidity and mortality rates in cattle were $22.24 \%$ \& 4.42\%, respectively. Reproductive (7.09\%) and digestive (5.14\%) diseases were major causes of morbidity in the study area. Adult cattle showed high (28.97\%) morbidity due to reproductive problems which are major challenges under village conditions in study area. Digestive (1.43\%) and nutritional $(0.85 \%)$ diseases were major causes of mortality of cattle. Chi-square analysis revealed that the morbidity was significantly $(p<0.01)$ related with age groups while mortality was significantly $(p<0.01)$ related with age and sex. Highest mortality rate (16.81\%) were observed among calves and male were at higher $(17.86 \%)$ mortality risk than that of female.
\end{abstract}

Conclusion: Morbidity and mortality studies provide an important tool for determining the health status and guidelines for managemental practices, which will ultimately help in increasing the milk production and improve the economic status of livestock owners.

Keywords: cattle, chi-square, digestive, morbidity, mortality

\section{Introduction}

Livestock sector plays an important role in the socio-economic development of the country and is important source of income for the farmers and poor rural people. The livestock industry success depends on the good health of the livestock that helps to increase the productivity. Whereas any compromise on health ground will shatter the hope of livestock sector. In spite of advancement made in the animal husbandry practices, clinical medicine and diagnostic techniques, the morbidity and mortality due to various causes continues to be higher in village areas. Shaikh [1] conducted study on morbidity and mortality in cattle covering four region of Maharashtra and reported that the overall morbidity and mortality rate in cattle was $19.22 \%$ \& 12.48\%, respectively. Higher morbidity among adults might be associated with stress during peak production period [2]. Maharashtra state had total 37.22 million livestock $(7.02 \%$ of the country's total livestock population), out of which 16.3 million comprises of cattle $(8.18 \%$ of country's total cattle population of India) [3]. Pune division had 2.4 million

This article is an open access article licensed under the terms of the Creative Commons Attribution License (http://creativecommons. org/licenses/by/2.0) which permits unrestricted use, distribution and reproduction in any medium, provided the work is properly cited. cattle population $(14.72 \%$ of total cattle population of Maharashtra). Total milk production from cattle for the state, during the year 2009-2010, was estimated to be 4.04 million tonnes $(54.6 \%$ of bovine milk production of the state) [4].

Since Pune division contributes a significant amount of milk production, this study has been undertaken to study the morbidity and mortality in cattle in this division.

\section{Materials and Methods}

The sampling scheme adopted for this study is Stratified two stages random sampling design was adopted. The Pune division of Maharashtra was divided into five strata taking each district (Pune, Satara, Kolhapur, Sangli and Solapur) as stratum from the division. From each stratum, four villages were selected randomly at first stage, and from each selected village, livestock owners were selected randomly at second stage. A total of 421 cattle owners were interviewed and information regarding demography, morbidity and mortality was recorded on a questionnaire for a period of 1 st of January 2010 to 31 st December 2010 on the basis of farmer's interview. The diseases observed during the study period were classified as Digestive, respiratory, reproductive, parasitic, specific, nutritional, injuries and other diseases categories [5]. 
Table-1. Distribution of cattle population maintained by livestock owners

\begin{tabular}{llcc}
\hline Variables & Class & No. of observed & $\%$ \\
\hline Male & Calf & 41 & 2.67 \\
& Youngstocks & 20 & 1.3 \\
& Adults & 163 & 10.6 \\
& Male-Total & 224 & 14.57 \\
Female & Calf & 298 & 19.38 \\
& Youngstocks & 254 & 16.51 \\
& Adults & 762 & 49.54 \\
& Female-Total & 1314 & 85.43 \\
Total & & 1538 & 100 \\
\hline
\end{tabular}

Table-2. Overall disease rates in cattle during study period

\begin{tabular}{lcccc}
\hline Disease category & Number of diseased & Morbidity rate $\%$ & Number of died & Mortality rate $\%$ \\
\hline Digestive & 79 & 5.14 & 22 & 1.43 \\
Respiratory & 37 & 2.41 & 11 & 0.72 \\
Reproductive & 109 & 7.09 & 2 & 0.13 \\
Parasitic & 14 & 0.91 & 7 & 0.46 \\
Specific & 8 & 0.52 & 2 & 0.13 \\
Nutritional & 28 & 1.82 & 9 & 0.85 \\
Injury & 18 & 1.17 & 2 & 0.59 \\
Others & 49 & 3.19 & 68 & 4.13 \\
Total & 342 & 22.24 & 1538 & 4.42 \\
Available & 1538 & & & \\
\hline
\end{tabular}

Statistical analysis: The collected data were compiled and analyzed by Chi-square analysis by SAS 9.3 software in the light of the objective of study to analyzed morbidity and mortality rates and factors affecting those rates. Morbidity rates and mortality rates were calculated on the basis of total prevalence during the period. Different formulae used for morbidity and mortality rates [6] were as below:

Morbidity rate $=$ Number of infected animals in the study area / Total animal population in study area X 100

Mortality rate $=$ Number of died animals in the study area / Total animal population in study area X 100

Chi-square $\left(\chi^{2}\right)$ analysis: For chi-square analysis of age-wise distribution of diseases/deaths, contingency table was made by using disease/death (yes and no) in rows and age (young, young stocks and adult) in column. Similarly for sex-wise distribution of diseases/deaths, contingency table was made by using disease/death (yes and no) in rows and sex (Male and Female) in column. The chi-square analysis for analyzing the categorical data by comparing the observed frequencies with expected frequencies done by using following formula,

$$
\chi^{2}=\sum \frac{(O-E)^{2}}{E}
$$

\section{Results and Discussion}

A total of 421 cattle owners were interviewed and information regarding the demography, morbidity and mortality rates was recorded. A total of 1538 cattle of different age group were maintained by 421 livestock owners selected for the study. Among 1538 cattle there were $224(14.57 \%)$ males and $1314(85.43 \%)$ female cattle. There were 339 calves, 274 young stocks and 925 adults of both male and female cattle (Table-1).

\section{Morbidity rate analysis:}

Overall morbidity rate: Morbidity related to various diseases categories in cattle out of 1538 animals a total
342 cattle were affected due to various disorders, this made annual prevalence rate $22.24 \%$ in cattle. Similar results were observed by Shaikh [1]. Reproductive diseases were more prominent in incidence having highest morbidity rate $(7.09 \%)$ followed by digestive disease $(5.14 \%)$ then other diseases occurred (3.19\%) and respiratory diseases $(2.41 \%)$ in cattle population at risk during given period (Table-2).

Chi-square analysis of overall morbidity data: The Chi-square analysis of overall morbidity rate in cattle with respect to age showed that age had significant $(p<0.01)$ effect while sex had no significant effect on morbidity rates in cattle (Table-3 and 4). High overall morbidity rate $(28.97 \%)$ was observed in adult age group cattle followed by calves (17.70\%) and youngstocks (5.11\%) (Table-3). This might be due to reproductive disorders and stress in peak production [2]. To avoid this situation, health groups and peoples working in animal husbandry sectors should give more attention to educate the farmers to provide extra rations during peak production and to give more information to avoid reproductive problems in cattle (Table-4).

Major causes of morbidity: Digestive diseases were major cause for causing morbidity in calves $(5.31 \%)$ and male (10.27\%) (Table-3). High incidence of digestive diseases in calves was reported by many workers Prasad et al. [5] and Gardner et al. [7]. Adult female cattle are more susceptible to reproductive disease.

\section{Mortality rate analysis}

Overall mortality rate: The crude mortality rate among cattle in survey area was found $4.42 \%$ i.e. 68 cattle out of 1538 cattle died due to various causes. Highest overall mortality rate $(1.43 \%)$ was observed due to digestive disease followed by nutritional diseases $(0.85 \%)$ in cattle population at risk during given period (Table-3). 
Table-3. Age-wise morbidity and mortality rates in cattle

\begin{tabular}{|c|c|c|c|c|c|}
\hline Age group & Young (< 1 yr) & Young stock (1 to 3 yrs) & Adult (>3 years) & Total & $\chi^{2}$ \\
\hline Total population & 339 & 274 & 925 & 1538 & \\
\hline Number of diseased & 60 & 14 & 268 & 342 & $74.79 * *$ \\
\hline Number of died & 57 & 4 & 7 & 68 & $158.29^{\star *}$ \\
\hline Overall morbidity rate $\%$ & 17.70 & 5.11 & 28.97 & 22.24 & \\
\hline Overall mortality rate $\%$ & 16.81 & 1.46 & 0.76 & 4.42 & \\
\hline \multicolumn{6}{|l|}{ Major cause } \\
\hline a) for morbidity & 5.31 (Digestive) & 1.46 (Injury) & 11.78 (Reproductive) & - & \\
\hline b) for mortality & 5.31 (Digestive) & 0.73 (Digestive) & 0.22 (Digestive) & & \\
\hline
\end{tabular}

**Significant at $1 \%$ level of significance

Table-4. Sex-wise morbidity and mortality rates in cattle

\begin{tabular}{lccc}
\hline Sex group & Male & Female & Total \\
\hline Total population & 224 & 1314 & 1538 \\
Number of diseased & 58 & 284 & 342 \\
Number of died & 40 & 28 & 68 \\
Overall morbidity rate $\%$ & 25.89 & 21.61 & 2.03 \\
Overall mortality rate \% & 17.86 & 2.13 & 4.24 \\
Major cause & & 8.30 (Reproductive) & \\
a) for morbidity & 10.27 (Digestive) & 0.61 (Injury) & \\
b) for mortality & 6.70 (Digestive) & \\
\hline
\end{tabular}

**Significant at $1 \%$ level of significance

Chi-square analysis of mortality data: Chi-square analysis of mortality pattern showed significance $(p<0.01)$ association among age categories and sex (Table-3 and 4). Highest mortality rate (16.81\%) was observed in calves than young stock $(1.46 \%)$ and adult $(0.76 \%)$ (Table-3). The higher mortality in calves might be due to poor management practices of calves and their increased susceptibility to diseases and environmental stress than older animals [8]. The age-wise mortality rates in cattle are in agreement with Santra et al. [9], Palanivel et al. [2] and Jindal et al. [10]. Male cattle showed maximum $(17.86 \%)$ mortality than female mortality $(2.13 \%)$ (Table-4). The reason for this may be given fact that more care is given to female cattle due to their economic importance as compared to their male counterparts. The results were in agreement with French et al. [11] and Kumar et al. [12].

Major causes of mortality: The major cause for High mortality rates in all age groups (calves: 5.31\%, youngstocks: $0.73 \% \&$ adult: $0.22 \%$ ) and male $(6.70 \%)$ cattle were digestive diseases (Table-4). Digestive problems are primary causes of mortality in cattle [1316].

\section{Conclusion}

Adult cattle showed high morbidity due to reproductive problems which are major challenges under village conditions in study area so major emphases are laid to attend reproductive problems. In this study, mortality rates were very high for calves and digestive diseases were major cause of morbidity \& mortality in calves suggesting that improvements in feeding and management care are needed for young animals. The male cattle were at higher risk morbidity $\&$ mortality due to digestive and nutritional diseases than that of female possibly because of lack of care due to their lower economic value. This study will provide the important tool for determining the health status of cattle \& for provide the guidelines for proper use of managemental practices which will ultimately help in increasing production and improvement of economic status of livestock owners.

\section{Authors' contribution}

YB and TAK designed the study. YB conducted study and analyzed the data. TAK and BS contributed drafted and revised the manuscript. AKD, DVK and NW helped to compiled and analysed data. All authors read and approved the final manuscript.

\section{Acknowledgements}

The authors are thankful to livestock owners of study area for providing necessary information. Financial support from Indian veterinary research institute is duly acknowledged.

\section{Competing interests}

The authors declare that they have no competing interest.

\section{References}

1. Shaikh, S. R. (2009) Estimation and analysis of morbidity and mortality in cattle under village condition of Maharashtra. M.V.Sc. Thesis submitted to Indian Veterinary Research Institute, Izatnagar, and Uttar Pradesh.

2. Palanivel, K. M., Vijayalingam, T. A., Selvasubramanian, S. and Mohanraj, M. (2007) A retrospective study on calf morbidity and mortality pattern in Tamil Nadu. Indian Journal of Field Veterinarians, 3(1): 41-43.

3. Livestock census (2007) DAHD. http://www.dahd.nic.in. Retrieved on 14-01-2013.

4. National accounting statistics (2011) http://www. indiastat. com. Retrieved on 12-01-2013.

5. Prasad, S., Ramachandran, N. and Raju, S. (2004) Mortality patterns in dairy animals under organised herd management conditions at Karnal India. Tropical Animal Health Production, 36: Pp.645-654.

6. Dana, S. S., Rathore, B. S. and Kaul, P. N. (2001) Morbidity and mortality pattern in desi cattle reared by the Santal tribe of West Bengal. Indian Journal of Animal Research, 35(1): 47-49.

7. Gardner, I. A., Hird, D. W., Utterback, W. W., Danaye Elmi 
C., Heron B. R., Christiansen, K. H. and Sischo, W. M. (1990) Mortality, morbidity, case fatality and culling rates for California dairy cattle as evaluated by the Animal Health Monitoring System, 1986-1987. Preventive Veterinary Medicine, 8(2): 157-170.

8. Duguma, B., Kechero, Y. and Janssens, G.P. J. (2012) Survey of Major Diseases Affecting Dairy Cattle in Jimma Town, Oromia, Ethiopia. Global Veterinaria, 8(1): 62-66.

9. Santra, A. K. and Pachalag, S. V. (1996) Mortality pattern in crossbred calves. Indian Journal of Animal Sciences, 66(3): 237-238.

10. Jindal, N., Kumar, S., Narang, G., Chaturvedi, G. C., Tomer, P. and Garg, D. N. (2002) Some epidemiological observations on haemorrhagic septicaemia in buffaloes and cattle in Haryana State of India. Buffalo Journal, 18(2): 273-280.

11. French, N. P., Tyre, J. and Hirst, W. M. (2001) Smallholder dairy farming in the Chikwaka communal land, Zimbabwe: Birth, death and demographic trends. Preventive Veterinary Medicine, 48(2): 101-112.

12. Kumar, C. R., Moorthy, P. R. S., Rao, K. S. and Naidu, K. V. (2002) Calf mortality pattern in relation to age and sex in organized livestock farms in Andhra Pradesh. Indian Journal of Animal Sciences, 72(10): 921-923.

13. Malik, S., Verma, A., Kumar, A., Gupta, M.K. and Sharma, S. D. (2012) Incidence of calf diarrhea in cattle and buffalo calves in Uttar Pradesh, India. Asian Journal of Animal and Veterinary Advances, 7(10):1049-1054.

14. Megersa, B., Yacob, A., Regassa, A., Abuna, F., Asmare, K. and Amenu, K. (2009) Prevalence and incidence rates of calf morbidity and mortality and associated risk factors in smallholder dairy farms in Hawassa, Southern Ethiopia. Ethiopian Veterinary Journal, 13(2): 59-68.

15. Mockeliunas, R., Sederevicius, A., Salomskas, A., Mockeliuniene, V., Maciulskis, P. and Jacevicius, E. (2005). Analysis of disease prevalence and mortality of cattle in Lithuania. Veterinarija ir Zootechnika, (32): 16-19.

16. Sischo W. M., Hird, D. W., Gardner, I. A., Utterback, W. W., Christiansen, K. H., Carpenter, T. E., Anaye elmi, C. D. and Heron, B. R. (1990) Economics of diseases occurrences and prevention on California dairy farm: A report and evaluation of data collected for the national animal health monitoring system, 1986-87. Preventive Veterinary Medicine, 8: 141-156. 